\title{
Paul Brinckmann, Wolfgang Frobin, Gunnar Leivseth, Burkhard Drerup: Orthopedic biomechanics
}

\author{
2nd Edition, Thieme Verlag, New York, Stuttgart, Delhi, Rio de Janeiro, August 2015, \\ 504 pp, Paper Back, 367 illustr. €79.99, ISBN: 978-3-13-176822-3
}

Pierre Kehr ${ }^{1}$

Received: 15 March 2016/Accepted: 25 April 2016/Published online: 29 June 2016

(C) Springer-Verlag France 2016

Biomechanics is very important for the good comprehension of the surgery of the bone joints and their prosthetic replacements.

This book will make it possible to understand the structure and the function of the human locomotor apparatus, to understand the factors of wear, to try to prevent them, and then to correct them.

This book will thus interest at the same time the surgeons but also the doctors for rehabilitation, and the engineers in the design of the prosthetic implants.

The first part treats basic elements of biomechanics and mathematics applied.

The second part relates to the locomotor apparatus: bone and cartilages, muscles, skin. It follows from there the study of the center of mass, moment of inertia, load articular, etc. before the application and study of the principal articulations: hip, knee, lumbar spine, shoulder, foot and to finish the study of walk.

The last part relates to exercises in the form of problems with their solutions.

The reader according to his knowledge will be able to read the book of the beginning with the fine if it is familiarized little with biomechanics, or to concentrate on certain chapters if it has already the bases. This book could be regularly consulted to learn or remind a particular technique.

Compliance with ethical standards

Conflict of interest None.

Pierre Kehr

pierre.kehr@gmail.com

1 Strasbourg, France 